\title{
Influence of environmental temperatures on the concrete compressive strength: simulation of hot and cold weather conditions
}

\author{
J. Ortiz $*^{\mathrm{a}}$, A. Aguado ${ }^{\text {b }}$ L. Agulló ${ }^{\mathrm{b}}$, T. García ${ }^{\mathrm{b}}$ \\ ${ }^{a}$ Ph.D. Candidate of Universitat Politècnica de Catalunya (UPC) and scholarship of CONACYT (México), C. Jordi Girona 1-3, \\ module C-1, 08034 Barcelona, Spain \\ ${ }^{b}$ E.T.S. Ingenieros de Caminos, Canales y Puertos UPC, C. Jordi Girona 1-3, module C-1, 08034 Barcelona, España
}

\begin{abstract}
This work has as objective to study the influence of mixing hour in the concrete properties such as workability and compressive strength in hot and cold weather conditions from an industrially applied point of view. The foremost studied variable was the concrete mixing hour, having used five mixing hours for every weather conditions. For each mixing hour, were carried out three concrete batches and 15 cylindrical concrete specimens were made for measuring compressive strength at 7 and 28 days. Besides, for each concrete batch the hydration kinetics was studied depending on the climatic situation and mixing hour. In the results regarding compressive strength, the best mechanical performances presented by the concrete correspond to the situation when the minimum difference between ambient temperature and concrete temperature exists; that is at later hours of the day for hot weather conditions.
\end{abstract}

Keywords: Concrete (E), Compressive Strength (C), Hot Weather, Cold Weather, Mixing Hour

\section{Introduction}

The fabrication of concrete with Portland cement in adverse weather conditions of high and low temperatures influences directly the concrete properties at any stage: mixing, transporting, casting and curing, as well as its physical and mechanical properties. It forms a concern for concrete producers and final users due to the evident consequences in technical and economical aspects.

A high ambient temperature causes a higher water demand of the concrete and increases the temperature of the fresh concrete. This, results in an increased rate of loss of slump and in a more rapid hydration, which leads to accelerated setting and to a lower long-term strength of concrete. [1] Besides, an increased rate of evaporation from fresh concrete results in a lower effective water content and hence lower effective water-cement ratio per weight. Moreover, concrete workability is reduced. This implies either an addition of water in order to restore the workability or an insufficient compacting. [2] Likewise in hot climates, there is a tendency for plastic cracking and crazing. As a result, a high temperature can adversely affect the mechanical properties and serviceability of hardened concrete. [3]

On the other hand, the chemical processes associated to the hardening of concrete in the first days after casting are accompanied by significant temperature changes, since cement hydration is a highly exothermic and thermally activated reaction. [4] The temperature variation caused by the heat of hydration or the change of external environment has a large influence on the mechanical properties of early-age concrete. Therefore, effects of temperature and aging on the mechanical properties must be studied and quantified. [5] 
Concerned with this problem, the UPC was proposed to achieve an experimental investigation relating these topics and with a final objective: "the optimization of the cement dosage into ready-mix concrete in adverse weather conditions, through the study of some concrete properties fabricated at different temperatures". This paper represents the first stage of the whole researching work. In this way, some other investigations have been made in order to accomplish this goal, among them we can cite the microstructural study of pastes and mortars in hot and cold weather conditions, the study of the absorption rate of aggregates at different temperatures, the study of the effect of temperature and dosage of admixture over the properties of cement paste in fresh state and the study of the thermal properties of aggregates. It is precise to say that this researching project is focused widely in the industrial developments and applications to ready-mix concrete production.

\section{Experimental program}

Laboratory testing of concrete is usually performed at a controlled temperature, normally constant. As the early testing was done in temperature climates, the standardized temperature chosen was generally in the region of 18 to $21^{\circ} \mathrm{C}$ so that much of the basic information about the properties of both fresh and hardened concrete is based on the behavior of concrete at these temperatures. In practice, however, concrete is mixed at a wide range of temperatures and also remains in service at different temperatures. In consequence, knowledge of the temperature effects in concrete is of great importance. [1] In this researching work, in order to know and quantify the influence of temperature over the concrete compressive strength, we have simulated variable thermal cycles (temperature and relative humidity) as a function of time.

\subsection{Thermal cycles used}

The conditions detailed in the ACI Committees 305 and 306 for "Hot Weather Concreting" and "Cold Weather Concreting" respectively, have been used as a reference frame for determining the weather conditions. [6, 7] Besides, in order to simulate realistic conditions concerning climatic and production situations, one day of maximum and minimum temperatures have been chosen for this study. Based on the temperature records of the Observatory Pompeu Fabra in Barcelona (Spain) [8], these days were the $24^{\text {th }}$ August 2000 for hot conditions and the $23^{\text {rd }}$ December 2001 for cold conditions.

Next, Fig. 1 (a) shows the temperature distribution for reference, hot and cold conditions. Likewise, the relative humidity for the three conditions is shown in Fig. 1 (b).
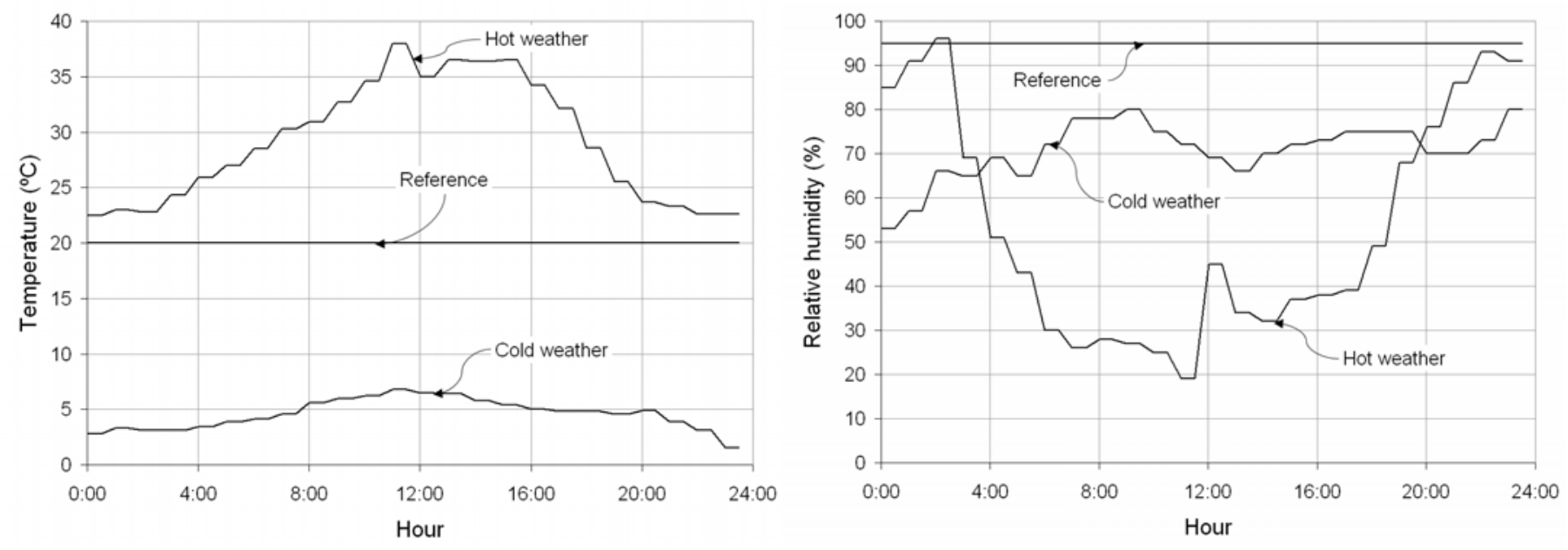

Fig. 1. Thermal cycle's representation (reference, hot and cold conditions)

(a) Temperature profiles, (b) Relative humidity profiles 
For the purpose of simulating the best these weather conditions, a climatic chamber able to be programmed with temperature and relative humidity data was installed. For the reference concrete, the temperature and relative humidity programmed in the chamber during 24 hours were $20^{\circ} \mathrm{C}$ (constant) and about $95 \%$ (constant), respectively.

In order to obtain the temperature profiles of concrete, thermocouple wires were introduced into concrete samples and were connected to a Squirrel data logger, besides one thermocouple was measuring the real ambient temperature. The thermal records were obtained every fifteen minutes.

\subsection{Studied variable}

The concrete mixing hour was chosen as the foremost studied variable; in this work five mixing hours were studied for each climatic situation. These mixing hours are the following: 10:00 hours, 11:30 hours, 13:00 hours, 14:30 hours and 17:30 hours for the case of hot weather, and for cold weather: 8:15 hours, 10:00 hours, 12:00 hours, 14:00 hours and 17:00 hours. Besides, three series of each thermal cycle were carried out, having then three sets of batches for each mixing hour for each weather condition. Parellelly with this work the concrete demolding ages also were studied in order to know its influence on the compressive strengh, nevertheless, in this specific case any influence was found. In this way, every series relates with one demolding age.

\subsection{Mix proportions and materials}

The concrete mix used in this work corresponds to a concrete of nominal strength of $25 \mathrm{MPa}$ with a watercement ratio of 0.55 . For the experimental concrete mix, the aggregates were angular crushed limestone with $20-\mathrm{mm}$ nominal maximum size, besides four different sizes of aggregates were used: $12-20 \mathrm{~mm}, 5-12 \mathrm{~mm}, 0-5 \mathrm{~mm}$ and 0-2 $\mathrm{mm}$. The specific gravity and absorption value for the aggregates are 2.72 and $0.37 \%, 2.67$ and $0.45 \%, 2.60$ and $1.60 \%, 2.57$ and $1.87 \%$, respectively. Ordinary Portland cement of $42.5 \mathrm{MPa}$ R (Type I) compressive strength was used and finally, a polyfunctional admixture with water reducing and setting retarding effects was used. The mixture proportions of concrete are given in Table 1.

Table 1

Concrete mix proportions

\begin{tabular}{cc}
\hline Material & Unit weight $\left(\mathrm{kg} / \mathrm{m}^{3}\right)$ \\
\hline Cement & $292 \mathrm{~kg}$ \\
Water & $162 \mathrm{lt}$ \\
Gravel $12-20$ & $830 \mathrm{~kg}$ \\
Gravel $5-12$ & $85 \mathrm{~kg}$ \\
Sand 0-5 & $860 \mathrm{~kg}$ \\
Sand 0-2 & $205 \mathrm{~kg}$ \\
Admixture $(0.70 \%)$ & $2.044 \mathrm{~kg}$ \\
\hline
\end{tabular}

\subsection{Preparation of specimens}

Prior to every concrete manufacture all the materials were stored in the climatic chamber during 72 hours in order to subject them to each climatic cycle. Concrete mixing was accomplished in a 50-liter capacity forced-mixing type mixer. In the mixing stage, the next sequence was followed to make the concrete batches: first with the mixer running the aggregates were introduced from greater to smaller particle size, then the water was added minus $300 \mathrm{ml}$ used later on to dilute the admixture. Immediately after, the cement was introduced and the concrete was mixed during 90 seconds. After these 90 seconds, the admixture was added together with the $300 \mathrm{ml}$ of water mentioned above and the entire batch was mixed for other 120 seconds. From each concrete batch the slump was measured and five cylindrical concrete specimens were made in order to obtain the compressive strength at the ages of 7 days (2 specimens) and 28 days ( 3 specimens). 


\subsection{Curing process}

Immediately after casting and compacting the concrete, the thermocouples were introduced into fresh concrete samples and thereafter the specimens were covered with plastic bags in order to avoid excessive water evaporation. Once having been the concrete specimens inside the climatic chamber for 24 hours (series 1), 48 hours (series 2) and 72 hours (series 3) corresponding to each thermal cycle they were demolding and stored in the curing chamber at a constant temperature of $20^{\circ} \mathrm{C}$ and $95 \%$ relative humidity until the compressive strength testing date of 7 and 28 days.

\subsection{Compressive strength testing}

The specimens of each concrete batch were moved away from the curing chamber at the ages of 7 and 28 days, thereafter compressive tests were performed using a hydraulic servocontrolled compressive testing machine. Before the testing, the top surfaces were capped with sulfur mortar. The compressive strength results were taken as the average values of the three series for each mixing hour, that is to say, six specimens for 7 days and nine specimens for 28 days.

\section{Test results}

\subsection{Thermal profiles}

Next in Fig. 2, the concrete thermal profile for 72 hours is shown for hot weather conditions. In this figures only one concrete batch has been plotted in order to make clearer the visualization of the curves.

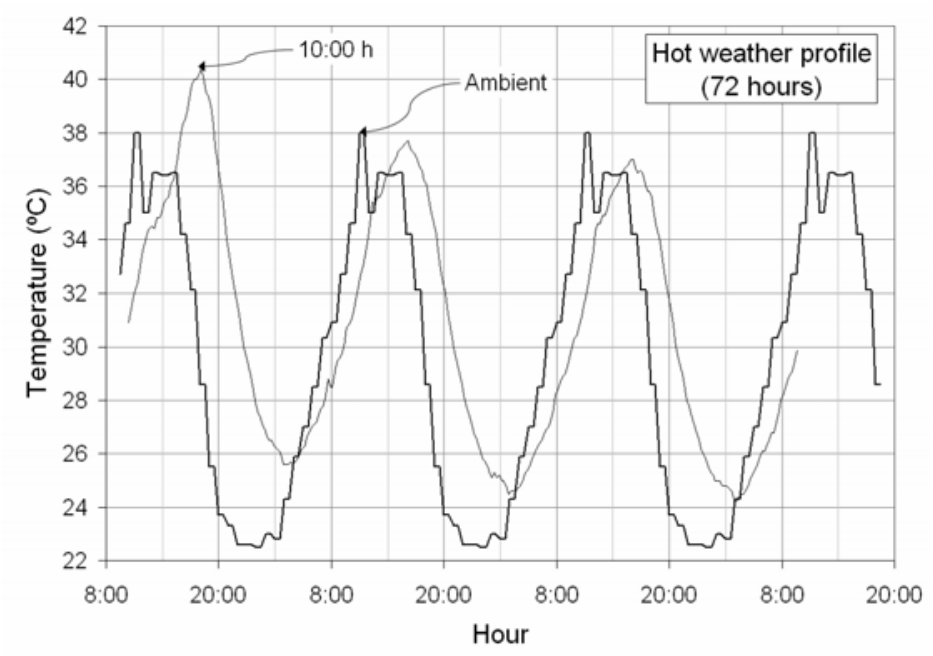

Fig. 2. Concrete thermal profile for 72 hours (hot weather)

In the last figures we can see that for the first 24 hours the concrete thermal evolution is affected by exothermic reactions of cement having a rise stage and a maximum peak temperature. Afterwards, after this time and further on, the concrete temperature follows the ambient temperature profile only having a little differential in time and in temperature due to concrete thermal inertia. For the thermal results, the stages to be studied will be the corresponding with the first 24 hours for all the climatic situations. 
The concrete thermal profiles for the first 24 hours obtained for reference, hot and cold weather conditions are shown below in Fig. 3 ( $a, b$ and c, respectively). Since for hot and cold weather conditions regarding each series, the thermal profiles were practically the same, only one representative profile is shown for each climatic situation. In order to explain how the thermal determinations were obtained, in the first figure corresponding to reference profile, the temperature increment $(\Delta \mathrm{T})$ between the initial temperature $\left(\mathrm{T}_{\mathrm{i}}\right)$ and the maximum temperature $\left(\mathrm{T}_{\max }\right)$ due to exothermic reactions of cement into concrete and the reaction time $(\Delta \mathrm{t})$ elapsed between the initial temperature moment $\left(\mathrm{t}_{\mathrm{i}}\right)$ and the maximum temperature moment $\left(\mathrm{t}_{\max }\right)$, are indicated in the plot.
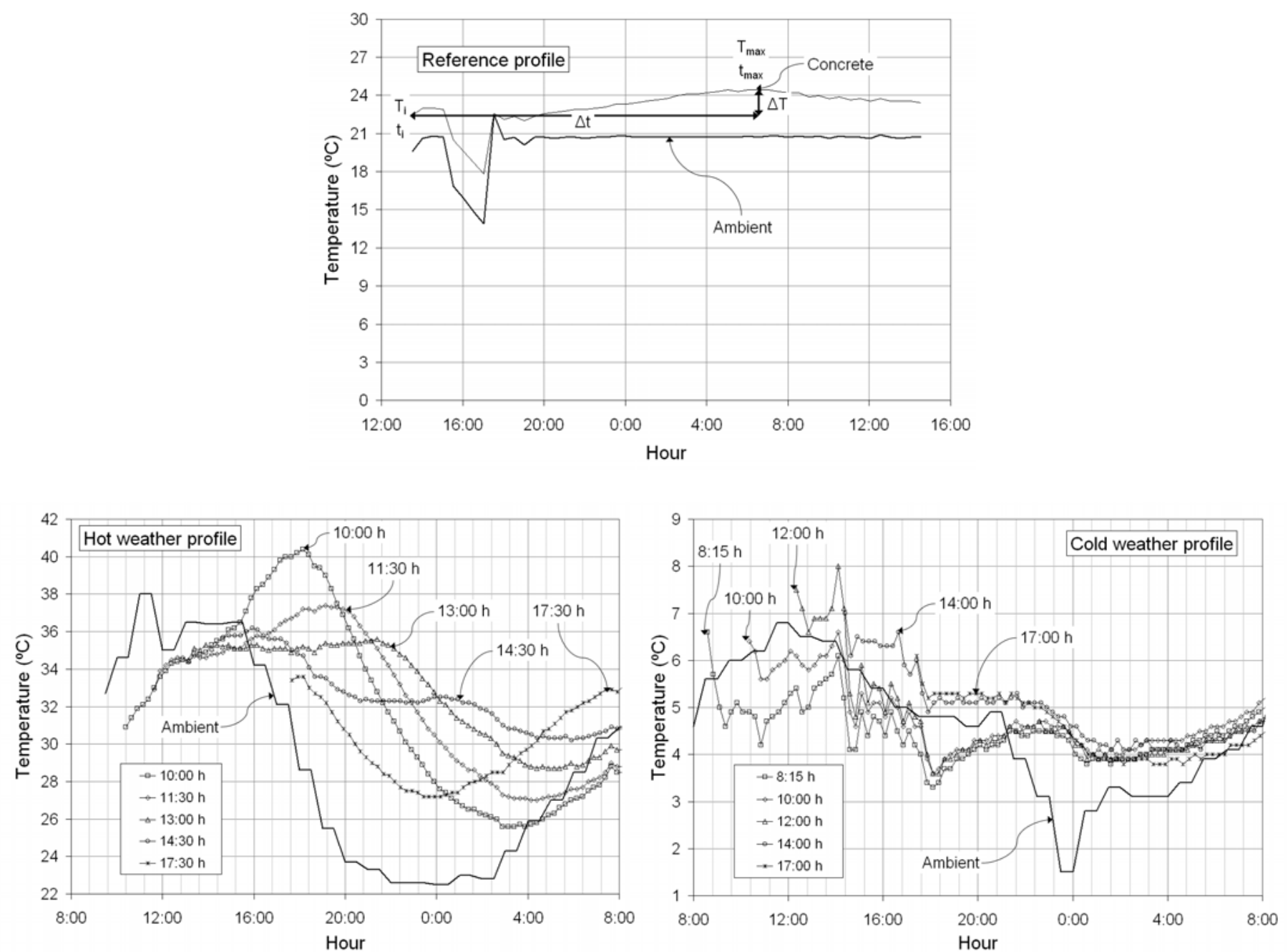

Fig. 3. Concrete thermal profiles

(a) Reference profile, (b) Hot weather profile, (c) Cold weather profile

In the case of hot weather profile we can point out that $\Delta t$ is greater at the later hours of the day and smaller at the first hours of the day. So that, when the increments of temperature $(\Delta \mathrm{T})$ due to both, ambient temperature and exothermic reactions are in the same sense (positive slope), the kinetics are faster and consequently $\Delta t$ is smaller. Equally, it can be seen that $\Delta \mathrm{T}$ decreases in the later hours of the day and vice versa. These minor increments of temperature could have a positive effect from the point of view of mechanical strength.

For the cold weather profile, the thermal evolution of concrete always follows the same tendency, i.e. nearly to the temperature ambient profile. Nevertheless it is remarked that the reaction times are longer than those from hot weather conditions. On the other hand the maximum temperatures $\left(\mathrm{T}_{\max }\right)$ reached by the concrete are smaller than those attained for hot weather conditions. In addition, from the point of view of mechanical strength these minor concrete temperatures could have positive effects. 


\subsection{Summary of thermal results}

By way of summary in Table 2 are presented the values of thermal increments $\left(\Delta T=T_{\max }-T_{i}\right)$ and reaction times $\left(\Delta \mathrm{t}=\mathrm{t}_{\max }-\mathrm{t}_{\mathrm{i}}\right)$ for all the climatic conditions studied. Besides, the data corresponding to thermal increments and reactions times is shown graphically in Fig. 4 and Fig. 5, respectively.

Table 2

Thermal increment $(\Delta \mathrm{T})$ and reaction time $(\Delta \mathrm{t})$

\begin{tabular}{ccccc}
\hline \multicolumn{5}{c}{ Hot weather conditions } \\
\hline Hour & $\mathrm{T}_{\mathrm{i}}\left({ }^{\circ} \mathrm{C}\right)$ & $\mathrm{T}_{\max }\left({ }^{\circ} \mathrm{C}\right)$ & $\Delta \mathrm{T}\left({ }^{\circ} \mathrm{C}\right)$ & $\Delta \mathrm{t}$ (hours) \\
\hline Reference & 22.4 & 24.5 & 2.1 & 17.00 \\
10:00 & 31.1 & 40.3 & 9.2 & 7.65 \\
$11: 30$ & 33.5 & 36.8 & 3.3 & 7.65 \\
$13: 00$ & 34.2 & 35.5 & 1.3 & 8.22 \\
$14: 30$ & 33.6 & 32.4 & -1.2 & 9.83 \\
$17: 30$ & 34.1 & 33.5 & -0.6 & 13.58 \\
\hline
\end{tabular}

\begin{tabular}{ccccc}
\hline \multicolumn{5}{c}{ Cold weather conditions } \\
\hline Hour & $\mathrm{T}_{\mathrm{i}}\left({ }^{\circ} \mathrm{C}\right)$ & $\mathrm{T}_{\max }\left({ }^{\circ} \mathrm{C}\right)$ & $\Delta \mathrm{T}\left({ }^{\circ} \mathrm{C}\right)$ & $\Delta \mathrm{t}$ (hours) \\
\hline Reference & 22.4 & 24.5 & 2.1 & 17.00 \\
$8: 15$ & 6.6 & 4.5 & -2.1 & 14.17 \\
$10: 00$ & 6.4 & 4.7 & -1.7 & 12.33 \\
$12: 00$ & 7.5 & 4.7 & -2.8 & 10.42 \\
$14: 00$ & 8.4 & 4.8 & -3.6 & 8.17 \\
$17: 00$ & 6.4 & 4.8 & -1.6 & 5.25 \\
\hline
\end{tabular}

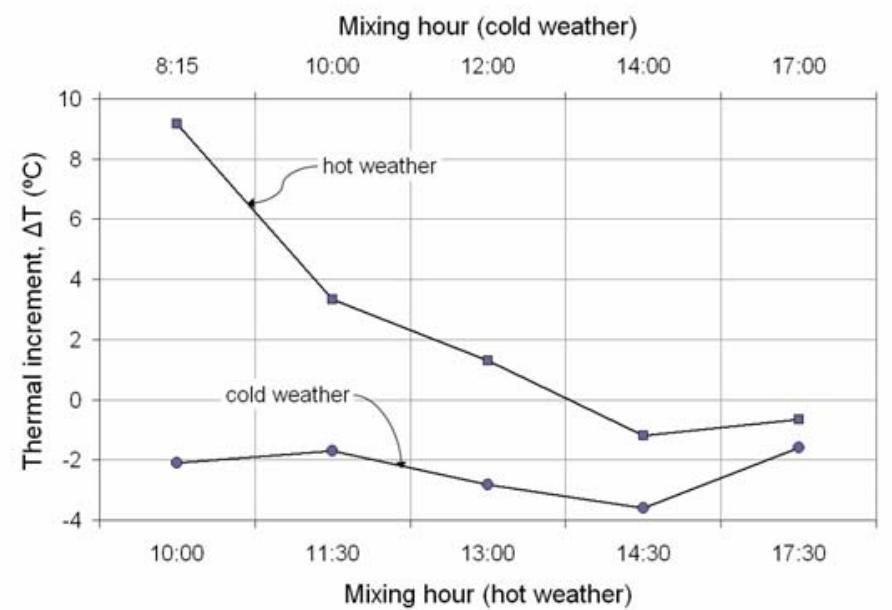

Fig. 4. Thermal increment for hot and cold weather

In the previous figure we can see that for hot weather conditions thermal increments present a falling tendency through the day, having a maximum increment at first hours of the day and a minimum value at later hours of the day. For the cold weather case, the tendency does not seem to follow a clear trend but rather presents a plain behavior through the day. 


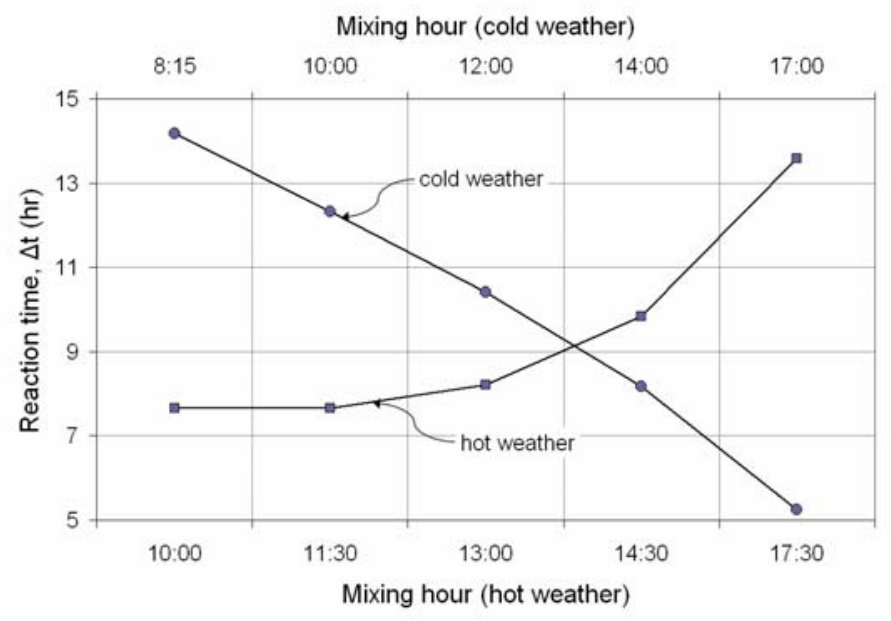

Fig. 5. Reaction time for hot and cold weather

Regarding reaction times for both weather conditions, it is evident an opposite tendency between them. So that, for cold weather conditions this tendency is falling and for hot weather conditions is growing, while moving forward on mixing hour.

All the facts mentioned above regarding thermal increments and reaction times can be explained saying that a rise in the curing temperature speeds up the chemical reaction of hydration and a higher temperature during and following the initial contact between cement and water reduces the length of the dormant period so that the overall structure of the hydrated cement paste becomes established very early. [1] We can remember here an axiom from physical chemistry, which states: the reaction velocity is doubled if the temperature at which the process is taking place is increased by $10^{\circ} \mathrm{C}$. [9]

According to the type of cement used in this work, it is important to cite that there is an optimum temperature during the early life of concrete that will lead to the highest strength at a desired age. For laboratory-made concrete, using ordinary or modified Portland cement, the optimum temperature is approximately $13{ }^{\circ} \mathrm{C}$; for rapid-hardening Portland cement it is about $4{ }^{\circ} \mathrm{C}$. It must not be forgotten, however, that beyond the initial period of setting and hardening the influence of temperature (within limits) accords with the maturity rule: a higher temperature accelerates the development of strength. [1]

\subsection{Compressive strength results}

The compressive strength results were obtained calculating the mean of all the concrete specimens for the three series of each mixing hour; i.e. for each mixing hour the average values used were from six specimens for 7 days and from nine specimens for 28 days.

In order to provide a statistical approach and visualize the inner dispersion of each series of data, the calculation of the single population variance through the pondered mean of all the sample variances is included. In this address, the generalized expression for calculating the standard deviation of a single population is the following equation (Eq. 1): [10]

$$
\mathrm{s}=\sqrt{\frac{\sum_{\mathrm{i}=1}^{\mathrm{k}}\left(\mathrm{n}_{\mathrm{i}}-1\right) \cdot \mathrm{s}_{\mathrm{i}}^{2}}{\sum_{\mathrm{i}=1}^{\mathrm{k}}\left(\mathrm{n}_{\mathrm{i}}-1\right)}}=\sqrt{\frac{\sum_{\mathrm{i}=1}^{\mathrm{k}}\left(\mathrm{n}_{\mathrm{i}}-1\right) \cdot \mathrm{s}_{\mathrm{i}}^{2}}{\mathrm{~N}-\mathrm{k}}}
$$

Eq.1. Expression for calculating data standard deviation 
where: $\mathrm{s}=$ standar deviation of a single population

$\mathrm{k}=$ number of treatmens to be compared

$\mathrm{n}_{\mathrm{i}}=$ number of data available corresponding to treatment $\mathrm{i}$

$\mathrm{s}_{\mathrm{i}}{ }^{2}=$ variance of data corresponding to to treatment $\mathrm{i}$

$\mathrm{N}=$ number of data in the $\mathrm{k}$ treatments

Besides, taking into account that our sample size is not so big such as to use a Normal Distribution, in this case we have used the Student's t-Distribution for calculating the scale factor according with the total degrees of freedom and with a statistical confidence interval of $90 \%$.

The values of slump and compressive strength at each test age for every mixing hour and for every climatic condition are presented below in Table 3. On the other hand, the coefficients of variation (expressed as percent) of average strength and the values of the standard deviation of a single population calculated for each weather condition depending on the testing age are shown for each mixing hour.

Table 3

Slump and compressive strength values at 7 and 28 days

\begin{tabular}{|c|c|c|c|c|c|c|c|}
\hline \multicolumn{8}{|c|}{ Hot weather conditions } \\
\hline \multirow{2}{*}{ Mixing hour } & \multirow{2}{*}{$\begin{array}{l}\text { Slump } \\
(\mathrm{cm})\end{array}$} & \multicolumn{2}{|c|}{ Compressive Strength(MPa) } & \multicolumn{2}{|c|}{ Coefficients of variation (\%) } & \multicolumn{2}{|c|}{ Standard deviation $(\mathrm{MPa})$} \\
\hline & & 7 days & 28 days & 7 days & 28 days & 7 days & 28 days \\
\hline Reference & 9.0 & 37.9 & 43.3 & 0.2 & 4.6 & 1.001 & 0.970 \\
\hline $10: 00$ & 4.5 & 34.3 & 40.9 & 2.5 & 5.2 & 0.869 & 1.044 \\
\hline $11: 30$ & 3.5 & 34.4 & 41.1 & 3.2 & 2.9 & 0.869 & 1.044 \\
\hline 13:00 & 3.5 & 35.2 & 41.9 & 4.6 & 2.8 & 0.869 & 1.044 \\
\hline $14: 30$ & 4.0 & 36.8 & 41.5 & 3.6 & 3.5 & 0.869 & 1.044 \\
\hline $17: 30$ & 3.2 & 37.3 & 42.5 & 3.2 & 6.6 & 0.869 & 1.044 \\
\hline
\end{tabular}

\begin{tabular}{cccccccc}
\hline \multicolumn{7}{c}{ Cold weather conditions } \\
\hline \multirow{2}{*}{ Mixing hour } & $\begin{array}{c}\text { Slump } \\
(\mathrm{cm})\end{array}$ & $\begin{array}{c}\text { Compressive Strength (MPa) } \\
\text { 7 days }\end{array}$ & Coefficients of variation (\%) & \multicolumn{2}{c}{ Standard deviation (MPa) } \\
\hline Reference & 9.0 & 37.9 & 43.3 & 0.2 & 4.6 & 1.001 & 0.970 \\
$8: 15$ & 7.0 & 41.7 & 45.8 & 2.2 & 2.8 & 1.175 & 0.847 \\
$10: 00$ & 7.5 & 41.7 & 45.7 & 4.4 & 1.5 & 1.175 & 0.847 \\
$12: 00$ & 7.0 & 41.6 & 45.5 & 3.1 & 3.7 & 1.175 & 0.847 \\
$14: 00$ & 6.5 & 40.4 & 46.7 & 4.3 & 3.5 & 1.175 & 0.847 \\
$17: 00$ & 7.5 & 40.6 & 46.0 & 5.4 & 4.2 & 1.175 & 0.847 \\
\hline
\end{tabular}

As we can see in the previous table it is remarked the influence of the ambient temperature on the fresh concrete workability having the most unfavorable situation for hot weather conditions in which the slumps values were very low. For the case of cold weather conditions the slump values were some higher but in any case these values were such as the reference one. In addition, it can be seen that for a particular weather condition the slump value does not have an important effect over the compressive strength of concrete.

For a more suitable visualization of the tendencies followed by the concrete at each mixing hour, in Fig. 6 the compressive strength of concrete at the ages of 7 days (a) and 28 days (b) are plotted for all the weather conditions; in this charts the bars with the standard deviation estimated are included. 

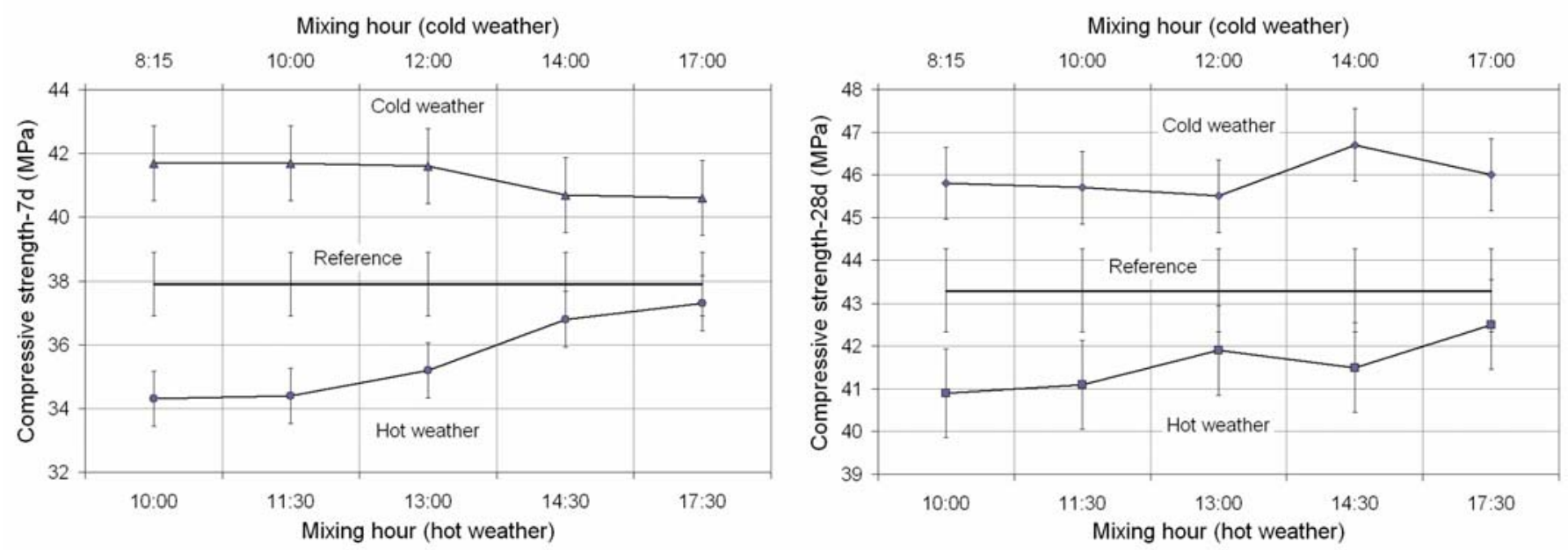

Fig. 6. Compressive strength results

(a) 7 days, (b) 28 days

Analyzing the compressive strength results, it is very evident that the magnitude of compressive strength values attained in cold weather are higher than the hot weather ones, in fact the 7 days compressive strength values of the cold weather concrete are almost similar to the 28 days compressive strength values of the hot weather concrete. Considering the standard deviation bars plotted in the compressive strength results, we can see that some overlaps exist between one point and another, mainly for cold weather conditions. Nevertheless, in this specific researching work one of our main goals was to develop an industrial application for ready-mix concrete production, so that, from the point of view of trends, the obtained results are very useful for being applied in this purpose.

In these results, the most influential factors are the concrete and ambient temperatures, and additionally the differential between these two temperatures, mainly in the first hours of the concrete. It is needful to emphasize the reverted tendency between hot and cold weather conditions in the sense of that the higher values of compressive strength in hot weather conditions corresponds to those of the later mixing hours, however for the case of cold weather conditions this tendency is inverse; i.e. the higher values of compressive strength are obtained in the first mixing hours. This tendency is more pronounced at the age of 7 days. In comparison to reference concrete strength values, we can say that all the strength values for hot weather conditions are lower and for the cold weather conditions, these strength values are higher. These effects can be related with the "crossover effect", as Alexander and Taplin referred this phenomenon: the concrete subjected to high temperature at an early age attains higher earlyage compressive strength but lower later-age compressive strength. [11]

\section{Discussion of results}

Mouret et al (1997) found that the amount of water required to produce a given consistency is generally increased with the rise of the aggregate temperature, besides, an evaporation of some amount of mixing water during casting and placing is observed. In addition, the extra water due to higher aggregate temperatures is not the main reason of the drops in concrete strengths. However, in this work non-extra water addition was carried out, but rather the same amount used in the reference concrete was used, so that such losses of workability were observed. These authors states that another explanation has to be investigated in the microstructure of concrete, i.e. the effect of aggregate temperature on the nature, the morphology and the distribution of hydration products in the internal space between the cement grains. In this respect, the counting of the unhydrated cement grains should provide more information about the hydration state of concrete as well as the evaluation of the combined water. On the other hand, previous studies have shown a microstructure change in the paste-aggregate interface for both summer concrete specimens and aggregate-paste models. Particularly, the higher the temperature of cement or/and aggregate, the greater the concentration of calcium hydroxide $(\mathrm{CH})$ at the interface. This observation leads to assume that the transition zone 
might be weakened by chemical phenomenon due to the rise of the constituent temperature. The authors found that elevated aggregate temperatures have the same effect as high curing temperature on the strength development of concrete. Since the greatest portion of concrete is aggregate, an increase in aggregate temperature brings about the greatest increase in concrete temperature. [2]

The effects of temperature on hydration and strength gain are still not well known. Rapid hydration due to elevated temperatures is considered to act as a "shell" than eventually hinders the diffusion of hydration products into the bulk cement paste matrix. The porosity of the bulk paste also is reported to increase as a result of non-uniform diffusion of the hydration products. Also, another effect may occur if the temperature is raised quickly during early ages. It may cause internal stresses exceeding the tensile strength of the immature concrete, which will lead to increased porosity, and cracking and a reduced strength potential. A rise in the early curing temperature makes hydration rate and concrete strength increase rapidly. But due to the non-homogeneous diffusion of hydration products and the difference in thermal expansion coefficients of concrete constituents, the porosity inside cement paste increases and micro-cracks develop, which finally lead to lowering the strength at the later time. [12]

Although a higher temperature during placing and setting increases the very early strength, it may adversely affect the strength from about 7 days onwards. The explanation is that a rapid initial hydration appears to form products of a poorer physical structure, probably more porous, so that a proportion of the pores will always remain unfilled. It follows from the gel/space ratio rule, that this will lead to a lower strength compared with a less porous, though slowly hydrating, cement paste in which a high gel/space ratio will eventually be reached.

This explanation of the adverse effects of a high early temperature on later strengths has been extended by Verbeck and Helmuth who suggest that the rapid initial rate of hydration at higher temperatures retards the subsequent hydration and produces a non-uniform distribution of the products of hydration within the paste. The reason for this is that, at the high initial rate of hydration, there is insufficient time available for the diffusion of the products of hydration away from the cement particle and for a uniform precipitation in the interstitial space (as is the case at lower temperatures).

As a result, a high concentration of the products of hydration is built up in the vicinity of the hydrating particles, and this retards the subsequent hydration and adversely affects the long-term strength. In addition, the non-uniform distribution of the products of hydration per se adversely affects the strength because the gel/space ratio in the interstices is lower than would be otherwise the case for an equal degree of hydration: the local weaker areas lower the strength of the hydrated cement paste as a whole. Also the quality of concrete depends on its temperature and not on that of the surrounding atmosphere, so that the size of the member also enters the picture because it affects the rise in temperature caused by the hydration of cement. [1]

As a summary, we can say that a faster and non-uniform precipitation of the products of hydration as a consequence of a curing process at a higher temperature, makes a structure more disordered and, in turn, the microstructural development is more heterogeneous and less compact (porous system); at the end, this effect is reflected in a minor increments of mechanical strengths over the time.

\section{Conclusions}

The obtained results, regarding concreting in extreme weather conditions, confirm the well known scenario that for cold weathers the compressive strengths are higher than for hot weathers. Likewise, in relation to workability the best results were attained in reference conditions and the worst under hot weather conditions.

On the other hand, concerning the mixing hour and based on the hydration kinetics and on the compressive strength results, some other specific conclusions are presented:

- For hot weather conditions is more convenient to place concrete in the later hours of the day when the ambient temperature will fall, in order to match the setting and hardening of the concrete with this falling stage of the external temperatures.

- For cold weather conditions is more convenient to place concrete in the early hours of the day when the ambient temperature will rise, in order to match the setting and hardening of concrete with this rising stage of the external temperatures. 
Finally, from an industrial point of view regarding compressive strength, the major conclusion is that for hot weather is more convenient to place concrete in the afternoon and for cold weather in the morning. This statement has been proven in realistic conditions over the production of a ready-mix concrete plant.

\section{Acknowledgements}

The authors wish to thank the support granted for the achievement of this set of works to Mr. Juan Puig and Mr. Domènec Masó of Grupo Cementos Molins, as well as the technical personnel of the Laboratory of Structural Technology of the Universitat Politècnica de Catalunya.

\section{References}

[1] A.M. Neville, Properties of Concrete (fourth edition), Pearson Education Limited, England, 1999.

[2] M. Mouret, A. Bascoul, G. Escadeillas, Cement and Concrete Research 27 (3) (1997) 345-357.

[3] K.A. Soudki, E.F. El-Salakawy, N.B. Elkum, Full factorial optimization of concrete mix design for hot climates, Journal of Materials in Civil Engineering 13 (6) (2001) 427-433.

[4] M. Cervera, R. Faria, J. Oliver, T. Prato, Numerical modelling of concrete curing, regarding hydration and temperature phenomena, Computers and Structures 80 (2002) 1511-1521.

[5] J.K. Kim, S.H. Han, Y.C. Song, Effect of temperature and aging on the mechanical properties of concrete. Part I. Experimental results, Cement and Concrete Research 32 (2002) 1087-1094.

[6] American Concrete Institute, ACI Manual of Concrete Practice: Part 2, ACI Committee 305, "Hot Weather Concreting (ACI 305R-91)". Farmington Hills. Detroit, Michigan. USA, 1991.

[7] American Concrete Institute, ACI Manual of Concrete Practice: Part 2, ACI Committee 306, "Cold Weather Concreting (ACI 306R-88)". Farmington Hills. Detroit, Michigan. USA, 1988.

[8] Servei Meteorològic de Catalunya (Departament de Medi Ambient, Generalitat de Catalunya), http://www.gencat.net/servmet/

[9] E. Rastrup, Heat of hydration in concrete, Magazine of Concrete Research, September (1954).

[10] A. Prat, X. Tort-Martorell, P. Grima, L. Pozueta, Métodos estadísticos - Control y mejora de la calidad, Edicions UPC, Barcelona, 1997.

[11] K.M. Alexander, J.H. Taplin, Concrete strength, cement hydration and the maturity rule, Australian Journal of Applied Science 13 (1962) 277-284.

[12] J.-K. Kim, Y.-H. Moon, S.-H. Eo, Cement and Concrete Research 28 (12) (1998) 1761-177. 